Review

\title{
Exploration of preferred learning styles in medical education using VARK modal
}

\author{
Laxman Khanal, Sandip Shah, Sarun Koirala \\ BP Koirala Institute of Health Sciences, Dharan, Nepal
}

Received 25 July 2014, Accepted 29 July 2014

(C) 2014, Khanal L., Shah S., Koirala S.

(C) 2014, Russian Open Medical Journal

\begin{abstract}
Learning styles is a term used to refer to the methods of gathering, processing, interpreting, organizing and thinking about information. Students have different learning styles, which is the reason for the diversity seen in classrooms in regards to how students acquire information. Claxton and Murrell had divided the learning styles into the following four categories: personality models, information-processing models, social-interaction models, and instructional preferences models. VARK (an acronym for Visual, Aural, Read/write and Kinesthetic, different way of learning styles) is a learning inventory categorized into the 'instructional preference' modal. Many studies were done using the VARK inventory among the medical education but the preferred mode of learning was variable in different parts of the world. The relationship of age, gender and academic performance with the mode of learning was also not consistent. So this article tried to conclude the preferred mode of learning and relationship of mode of learning with gender and other factors by analyzing the previous studies done using VARK questionnaire among the medical students in daily teaching and learning environment. Pub Med and Google Scholar were used as a search engine to find the article. Altogether 20 full text research papers were retrieved and reviewed. In the most of part of the world the studies showed that multimodal learning style was the predominant one over unimodal. Further in multimodal quadmodal was the most preferred one followed by other presentation. In the unimodal presentation most preferred one is kinesthetic type of learning along with visual, aural and read write in less extent. Age factors had no lucid relationship with the learning style though some variations were observed with age.This review was expected to be useful as scientific evidence in the field of medical education and also as a reference for further research.
\end{abstract}

Keywords: learning style, VARK, medical students, learning inventory

Cite as Khanal L, Shah S, Koirala S. Exploration of preferred learning styles in medical education using VARK modal. Russian Open Medical Journal 2014; 3: 0305

Correspondence to Dr. Laxman Khanal. Phone: 0097702552555. Mobile: 009779847825483. E mail: laxman.khanal.bpkihs@gmail.com

\section{Introduction}

Medicine is not only a science of factual knowledge about health and disease, rather It is a systematized knowledge of the human body in health and disease along with sociological side of medicine, which is so intricate, so vast and comprehensive, that it actually embraces almost every sphere of human activity [1]. It is considered that history of medical education began with the ancient Greeks' method of rational inquiry. Apprenticeship training in monastic infirmaries and hospitals dominated medical education during the early middle Ages. A medical school in anything like its present form, however, did not evolve until the establishment of the one at Salerno in Italy between the 9th and 11 th centuries [2]. It was not until the mid- $19^{\text {th }}$ century that an ordered pattern of science-oriented teaching was established which was based upon teaching, where the student mostly listens, rather than participating activity where the student is more investigative [3]. Later medical education eventually developed into a process that involved four generally recognized stages: premedical, undergraduate, postgraduate, and continuing education. Medical schools usually begin their work with the study of the structure of the body and its formation: anatomy, histology, and embryology. Concurrently, come studies related to function i.e., physiology, biochemistry, pharmacology, and, in many schools, biophysics. After the microscopic study of normal tissues (histology) has begun, the student is usually introduced to pathological anatomy and microbiology [4].

Every teaching methodology has its pros and cons. Effective lectures combine the talents of scholar, writer, producer, comedian, showman and researcher in ways that contributed to students learning as well stated by McKeachie [5]. Dr. Malcolm Knowles' theory about adult learning is widely accepted and is based on the principle that learning should be "learner-centered". As adults learn, they move from a dependent state to one that is more self-directed. One way to encourage students' active involvement in their education is to give them tools to help them become better learners regardless of the setting in which they are learning. One tool that can be used to facilitate this is a learning style inventory [6]. The teachers can address learner's needs by utilizing a variety of teaching methods and teaching styles so that learners are exposed to both familiar and unfamiliar ways of learning, ultimately giving learners multiple ways to excel [7].

Learning styles is a term used to refer to the methods of gathering, processing, interpreting, organizing and thinking about information. Students have different learning styles, which is the reason for the diversity seen in classrooms in regards to how students acquire information. Claxton and Murrell had divide the 
learning styles into the following four categories: personality models, information-processing models, social-interaction models, and instructional preferences models. The personality models examine a person's personality characteristics such as introversion vs. extroversion. This gives the student information on how they are likely to react to information and situations. The informationprocessing models focus on how students take in and process information. It determines, for example, if the person learns in a serial manner or by looking at the whole concept. The socialinteraction models determine how a student reacts and behaves in the classroom. This model, for example, can be used to determine if a student is motivated by grades or by interest in material content. Finally, the instructional preferences models differentiate students by the way in which they best acquire information. For example, does the student learn best by listening, reading, visualizing or experiencing [8]? There have been various models developed to explain different learning styles including Kolb's Learning Inventory, Gardner's Multiple Intelligence Theory. The Kolb model has been criticized for not applying to all situations, for paying insufficient attention to the process of reflection, and the relationship of learning processes to knowledge $[9,10]$. In fact, a literature review identified 71 different theories of learning styles [11]. This review identifies researches undertaken by using 'Instructional preference model' within the everyday learning environment which are found to have more immediate practical relevance $[7,12]$.

VARK (an acronym for Visual, Aural, Read/write and Kinesthetic, different way of learning styles) is a learning inventory categorized into the 'instructional preference' modal [6]. Developed in 1987 by Neil D. Fleming, an educator for more than forty years, the VARK inventory was developed in an effort to improve faculty development and to help students become better learners (Figure 1). Visual (V) learners process information best if they can see it. Graphs, flow charts and pictures are helpful to them. Aural (A) learners like to hear the information and process information best by listening to lectures, attending tutorials and using tape recorders to play back learning sessions. The " $R$ " (read/write) learners like to see the written words. They like to read text and take notes verbatim and reread these over and over again. Finally, kinesthetic (K) learners like to acquire information through experience and practice, and prefer to learn information that has a connection to reality. The additional "multimodal" category encompasses the students who fall into more than one sensory modality of any combination (Bi, Tri or Quad modal) [6, 13]. Use of VARK inventory among thousands of college-aged students suggest that auditory and kinesthetic modes of learning predominate in the general population of college students [14]. But precise conclusion about teaching learning activity about medical students was not concluded.

Recent research indicates that students' learning styles and approaches to study may have a significant bearing on their academic success [15]. Some studies had suggested that becoming aware of their learning style helps students learn, as students perceive that 'the intervention 'was useful in improving their learning. There was less agreement among students that knowing their learning style helped their performance in exams $[16,17]$. The questionnaire can motivate teachers to move from their preferred mode(s) to student's preferred mode (s). In so doing, they can reach more students because of the better match between teacher and learner styles [18]. Studies done using the 'VARK model' were used in the present study because it was accompanied by study strategies for each style; it could help in formulating teaching strategies; and finally due to its simplicity and reliability [19]. Many studies were done using the VARK inventory among the medical education but the preferred mode of learning was variable among the medical students in different parts of the world. The relationship of age, gender and academic performance with the mode of learning was also not consistent. So this article tried to conclude the preferred mode of learning and relationship of mode of learning with gender and other factors by analyzing the previous studies done using VARK questionnaire among the medical students in daily teaching and learning environment. This review was expected to be useful for the field of medical education where the researches were not done using VARK to understand the preferred mode of education. The conclusion of this review could be taken as a reference for teaching and learning activity along with for further research using VARK inventory and also to compare the outcome of result regarding teaching and learning activities of medical students.

\section{Material and Methods}

The idea of this study came from the daily involvement in teaching learning activities in BP Koirala Institute of Health Sciences (Dharan, Nepal). Authors personally observed variable learning preference among the undergraduate students in same institute, which provoke the idea about knowing the trends in literature. Further, experts in the medical education were consulted to design the study. This study identified researches undertaken within the everyday learning environment using VARK learning inventory. Since the development of VARK inventory for determining the preference learning style, ample amount of researches were done in various field of education including medical education. Study was designed by searching the articles using the key word: VARK, Medical education or Medical student and Learning style, within fifteen year range of time period. PubMed and Google Scholar were used as a search engine to find the article. Full text articles were retrieved by requesting the publication journal and by using HINARI from the institute. Altogether 20 full text research papers were retrieved from search engine. All the research papers were analyzed by taking into account of main objective, subject's characteristic (age, gender and level of medical education: preclinical, clinical, post graduate), and different modes of learning with the help of educational expert of Department of medical education.

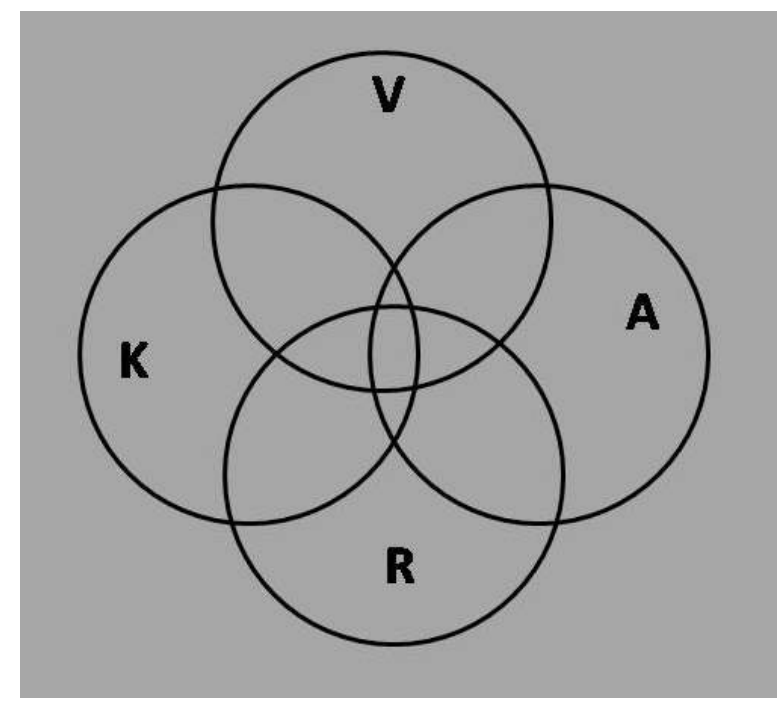

Figure 1. Components of VARK modal 
Table 1. Summary result of previous studies in chronological order

\begin{tabular}{|c|c|c|c|c|c|c|c|}
\hline \multirow[t]{2}{*}{ Author } & \multirow[t]{2}{*}{ region } & \multirow[t]{2}{*}{ Sample size } & \multirow[t]{2}{*}{ Level } & \multicolumn{2}{|c|}{ Multimodal } & \multicolumn{2}{|c|}{ Unimodal } \\
\hline & & & & Frequency & Preferred modal & Frequency & Preferred modal \\
\hline Marcy V (2001) & USA & 18 & UG (C) & $72.2 \%$ & & $27.8 \%$ & $\mathrm{R}-80.0 \%$ \\
\hline $\begin{array}{l}\text { Baykan and } \\
\text { Nacarn (2006) }\end{array}$ & Turkey & 162 & UG (P) & $63.9 \%$ & Quadmodal (20.2\%) & $36.1 \%$ & $\mathrm{~K}=23.3 \%$ \\
\hline Lujan et al. (2006) & USA & 166 & UG $(P)$ & $63.8 \%$ & Quadmodal (43.4\%) & $36.1 \%$ & $\mathrm{~K}=18.1 \%$ \\
\hline $\begin{array}{l}\text { Wehrwein et al } \\
\text { (2007) }\end{array}$ & USA & 86 & UG (P) & $\begin{array}{l}' M^{\prime}-77.5 \% \\
' F^{\prime}-45.8 \%\end{array}$ & $\begin{array}{c}\text { Quadmodal } \\
\text { ('M'-58.3\%, 'F'- } \\
20.8 \%)\end{array}$ & $\begin{array}{c}{ }^{\prime} \mathrm{M}^{\prime}-12.5 \% \\
54.2 \%\end{array}$ & $\begin{array}{c}{ }^{\prime} \mathrm{M}^{\prime}-\mathrm{A}=\mathrm{R}=\mathrm{K}(4.2 \%) \\
{ }^{\prime} \mathrm{F}^{\prime}-\mathrm{K}(33.3 \%)\end{array}$ \\
\hline Slater et al (2007) & USA & 97 & UG (C) & $56.4 \%$ & Quadmodal (47.17\%) & $43.62 \%$ & $\mathrm{~K}-51.21 \%$ \\
\hline $\begin{array}{l}\text { Breckler et al. } \\
(2009)\end{array}$ & USA & 218 & UG & $60.0 \%$ & Quadmodal (61\%) & $40 \%$ & $\mathrm{~K}(60 \%)$ \\
\hline $\begin{array}{l}\text { Johnson, Mary } \\
(2009)\end{array}$ & USA & 74 & UG & $52.4 \%$ & & $47.6 \%$ & $\mathrm{R}(44.9 \%)$ \\
\hline $\begin{array}{l}\text { El Tantawi, Maha } \\
\text { Ma (2009) }\end{array}$ & Egypt & 57 & PG & $73.7 \%$ & Quadmodal (42.87\%) & $26.3 \%$ & $A=K(39.92)$ \\
\hline $\begin{array}{l}\text { Dobson, John L } \\
\text { (2010) }\end{array}$ & & 64 & UG and PG & $71.0 \%$ & Quadmodal (52.1\%) & $29 \%$ & $\mathrm{R}(48.27 \%)$ \\
\hline $\begin{array}{l}\text { Choudhary et al } \\
(2011)\end{array}$ & India & 155 & UG (P) & $\begin{array}{l}\text { 'M'-92.9\% } \\
\text { 'F'-76.3\% }\end{array}$ & Trimodal & $\begin{array}{l}'{ }^{\prime} \mathrm{\prime}-6.25 \% \\
{ }^{\prime} \mathrm{F} '-23.75 \% \\
\end{array}$ & $\begin{array}{l}\text { 'F'-K } \\
\text { 'M'-R }\end{array}$ \\
\hline Ramirez B (2011) & Spain & 312 & UG $(P+C)$ & $68.9 \%$ & & $26-37 \%$ & 'K' \\
\hline $\begin{array}{l}\text { Hamouzadeh et al } \\
(2011)\end{array}$ & Iran & 130 & $\begin{array}{c}\text { Health } \\
\text { management }\end{array}$ & $66.9 \%$ & $\begin{array}{c}\text { Quadmodal } \\
(52.91 \%)\end{array}$ & $33.1 \%$ & 'K' (32.62\%) \\
\hline Kumar (2012) & Mauritius & 208 & UG (C) & $75.9 \%$ & Quadmodal-48.07\% & $24.02 \%$ & $\mathrm{~V}-70 \%$ \\
\hline Ubah JN (2012) & Nigeria & 117 & UG (C) & $91.5 \%$ & & $8.5 \%$ & $\begin{array}{l}\text { 'R'- female } \\
\text { 'K'-male }\end{array}$ \\
\hline Sinha et al (2013) & Malaysia & 176 & UG (C) & $56 \%$ & Bimodal & $44 \%$ & 'K'-45\% \\
\hline $\begin{array}{l}\text { Nuzhat et al } \\
(2013)\end{array}$ & Saudi Arabia & 146 & UG (C) & $\begin{array}{l}'{ }^{\prime}{ }^{\prime}-79.7 \% \\
' F '-65.3 \%\end{array}$ & $\begin{array}{l}\text { Trimodal for both } \\
\text { 'M' and ' } F \text { ' }\end{array}$ & $\begin{array}{l}\text { 'M'-20.3\% } \\
\text { 'F-'34.7\% } \\
\end{array}$ & $\begin{array}{c}\text { 'A' for both 'M'and } \\
\text { 'F' }\end{array}$ \\
\hline $\begin{array}{l}\text { Samarakoon et al } \\
(2013)\end{array}$ & Sri Lanka & 147 & UG and PG & $\begin{array}{c}\text { UG-69.99 \% } \\
\text { PG-47.1\% }\end{array}$ & $\begin{array}{c}\text { UG-AR=50\% } \\
\text { PG-Ak=31.8\% }\end{array}$ & $\begin{array}{l}\text { UG-30.1\% } \\
\text { PG-52.9\% } \\
\end{array}$ & $\begin{array}{c}\text { UG-A (50\%) } \\
\text { PG-K (33.4\%) }\end{array}$ \\
\hline $\begin{array}{l}\text { Shenoy et al } \\
(2013)\end{array}$ & India & 200 & PG & $\begin{array}{l}'{ }^{\prime}-48.7 \% \\
' F^{\prime}-51.3 \%\end{array}$ & Quadmodal (50.66\%) & $\begin{array}{l}\mathrm{M}^{\prime}-47.9 \% \\
' \mathrm{~F}^{\prime}-52.1 \%\end{array}$ & $\begin{array}{c}\mathrm{K}(52.1 \% \text { ' } \mathrm{M} \text { ' and } \\
47.9 \% \text { ' } \mathrm{F} \text { ' of } \\
\text { unimodal type) }\end{array}$ \\
\hline Kharb et al (2013) & India & 100 & UG $(P)$ & $61 \%$ & Bimodal (VA) & $39 \%$ & $\mathrm{~K}=26 \%$ \\
\hline Mon et al (2014) & Malaysia & 98 & UG (P) & $62.2 \%$ & Quadmodal (43.9\%) & $37.8 \%$ & $\mathrm{R}(13 \%)$ \\
\hline $\begin{array}{l}\text { Whillier et al } \\
\text { (2014) }\end{array}$ & Australia & 407 & UG and $P G$ & $56.0 \%$ & & $44 \%$ & $\mathrm{~K}$ \\
\hline
\end{tabular}

UG - undergraduate, PG - post graduate, V - visual, A - aural. $R$ - read/write, $K$ - kinesthetic, ' $M$ ' - male, ' $F$ ' - female, (P) - preclinical, (C) - clinical.

\section{Review and Discussion}

\section{Most preferred VARK modals (Table 1)}

There is a trend in University teaching to instruct all students in the same way (i.e., a straight lecture format). Educators use this lecture format because of the relative ease of information passing, the need to cover the content, a long history of traditional lecturing and perhaps due to their own preferences in learning. The results of the VARK questionnaire should convince teachers to use multiple modes of information presentation. This may require instructors to stray from their own preferred modes of teaching and learn to use a variety of styles, which will positively affect learning [20]. All the physically unimpaired students tend to use all their senses to receive and process information that passed to them. There is a possibility that multi- modal learners have the advantage compared to unimodal learners, which gives them a better chance for the admission into medical schools [21]. Neuroscience research has also revealed that significant increases in learning can be accomplished when the learning environments cater to their predominant learning styles. This is known as the "meshing hypothesis" [22]. According to the VARK website, of the 45,826 respondents (general population), $27.8 \%$ are kinesthetic, $27.4 \% \mathrm{read} /$ write, $24.5 \%$ aural, and $20.5 \%$ visual [23]. A cross sectional study done by Kharb et al on 100 first semester medical students of India showed that $61 \%$ of the students had multimodal VARK preferences. Among them bimodal (41\%) dominated over trimodal (14\%) and quadmodal (6\%) ways of information presentation. Among the respondent who had unimodal learning preference $(39 \%)$, The most common unimodal preference was kinaesthetic, followed by visual, auditory and read and write [19]. Kinesthetic $(K)$ learners like to acquire information through experience and practice, and prefer to learn information that has a connection to reality [13]. Later statement was proved by exploring the preferred teaching methodology which was key work done in this study. Most of the students choose practical and dissection as a preferred mode and lecture and tutorial as a least preferred mode of teaching. A positive correlation (Pearson's correlation coefficient, $r=0.752$ ) was observed between the preferences of the VARK modes and the preferred teaching learning methods [19]. Similar findings were shown by study done by Baykaarn and Nacar among the 155 medical students of Turkey by using Turkish version of VARK questionnaire which showed that unimodality preference was $36.1 \%$ (23.3\% were kinesthetic, $7.7 \%$ were auditory, $3.2 \%$ were visual, and $1.9 \%$ were read-write learners) and multimodality was $63.9 \%$ (30.3\% were bimodal, $20.7 \%$ were trimodal and $12.9 \%$ were quadmodal) [24]. In 
conclusion both of the study mentioned had similar preferences in unimodal and multimodal learning style. Study done by Ramirez amomg 312 undergraduate students from different classes showed predominant learning modal as multimodal in $68.9 \%$ and unimodal in about $35 \%$ with Kinesthetic learning as a predominant presentation [25]. Study done by Breckler et al among undergraduate and graduate students showed that about $60 \%$ of students were multimodal learners and $40 \%$ were unimodal learners. The $\mathrm{K}$ learning preference was the most common unimodal learning preference [16]. Similar findings were also seen by Hamouzadeh et al among the medical students of Teharan, by J. Ubah among Nigerian medical students and by Sinha et al among final year medical student of Malaysia and by Choudhary and Dullo among Indian students [20, 26-28].

Since major way of learning was multimodal, this implies that most of the students learn effectively as long as the teaching methods include a blend of activities that stimulate the visual, aural, read-write and the kinesthetic sensory modalities. The increasing use of multimedia in teaching can provide opportunities for presenting multiple representations of the content (text, video, audio, images and interactive elements) to cater more effectively to the diverse learning styles of the students. Since the preferred unimodal presentation was kinesthetic, thus most students may benefit from active learning strategies over the traditional lecture format. Active learning strategies reach all types of learners in the multiple schemes (visual, auditory, reading/writing, and kinesthetic). The variations in the learning preferences of the medical students from different countries could be explained on the basis of the differences in the teaching methodologies which are being used at the premedical level and the exposure to the hands on clinical experiences in the first year of the medical curriculum [19].

The study done by Lujan et al among 166 first year medical students of Wayne state University of Medicine showed that $36.1 \%$ of the students preferred a single mode of information presentation. Among these students, 5.4\% preferred visual, $4.8 \%$ preferred auditory, $7.8 \%$ preferred reading and writing, and $18.1 \%$ preferred kinesthetic learning. In contrast, most students (63.8\%) preferred multiple modes [ 2 modes (24.5\%), 3 modes (32.1\%), or 4 modes (43.4\%)] of information presentation [18]. Study done by Dobson among medical students showed that most common method of learning was quadmodal (VARK) followed by unimodal (A) [29]. Similar findings were also observed by Choudhary and Dullo [20].

The study done by Whillier et al among 407 ( $41.4 \%$ females) full-degree, undergraduate, and postgraduate students enrolled in an Australian chiropractic program (year 1 to 5) showed that majority $(56.0 \%)$ of the students were found to be multimodal learners with most of them appeared to have kinesthetic preference. The outcome of this study also indicated that both (multimodal and unimodal) presentations did not change over the course of study[30]. The study by Turner et al also identified the similar result regarding learning preferences of pediatric residents using VARK and the Kolb Learning Style Inventory. They showed a significant preference for kinesthetic learning $(p<0.01)$, which also was represented as an interactive learning style preference on the Kolb inventory $(p<0.01)$. Of the 50 residents, $90 \%$ were Kinesthetic, $76 \%$ Read/ Write, $66 \%$ Aural, and $62 \%$ Visual, and $80 \%$ were multimodal [31].

Study done by Shenoy et al among the 200 junior resident $(98$ male and 102 females) of India was found to be very important due to its observation in three aspects: it assessed the learning style preferences, assessed gender difference and correlate the academic grade to the preferred learning style. Of the total students, $29.3 \%$ students ( 23 males and 26 females) preferred the unimodal learning and $70.7 \%$ students ( 74 males and 78 females) preferred the multimodal learning. Among the multimodal learners, 25\% students preferred the bimodal learning, $24.3 \%$ preferred the trimodal learning and $50.66 \%$ preferred the quadmodal learning. Most common unimodal presentation was auditory like the study of Dobson and unlike most of other study where most common unimodal presentation was Kinesthetic [32]. This might be due to the fact that the students had come to terms with the teaching style which was adopted and which was predominantly didactic lectures as the authors claimed.

Study done by El Tantawi among 57 postgraduate dental students of Egypt showed that Only 26.3 percent of the students had a single dominant learning preference, while 73.7 percent had multiple learning preferences in different combinations. The most prevalent learning style preference among students was multiple: a combination of all four styles - VARK (31.6\%), followed by a combination - ARK (14\%). This was followed by Auditory and Kinesthetic as single dominant learning preferences $(10.5 \%$ for each) [33]. The high score of kinesthetic presentation among dentist was rationalized by the fact that they began their clinical training and then settled into professional life, which is dominated by manual activity and accumulating experiences by contact with each new patient. Study done by Johnson among 74 first year medical students of USA had also found that majority of students prefer to learn from multimodal presentation [34]. Similar result was also observed by A. Kumar [35] and V. Marcy [6]. Study done by Marcy among First-year Emory University Physician Assistant students $(n=18)$. Thirteen of the students fell into the multimodal category, four fell into the read/write category and one person fell into the kinesthetic category.

Study done by Slater et al. among the first year medical students of Wayne State University observed that both male (56.1\%) and female $(56.6 \%)$ students reported a preference for learning that utilizes multiple sensory modalities over unimodal learning (43.9\% of male students and $43.3 \%$ of female students). Quadmodal type of presentation was the most preferred for both genders [21]. This was not surprising observation because all physically unimpaired students are supposed to be multimodal, using all their senses to take in information at any given time.

\section{Learning style and level of medical education}

Teaching by Didactic type of lecture activity plays major role in Secondary education in schools, encouraging students towards auditory and read/write learning styles while Advanced Level examination is a norm-referenced competitive examination which determines entry to the universities. According to Samarakoon et al., first year medical students would be expected to favour auditory and read/write learning styles and strategic learning, while final year students would be expected to switch to multimodal learning styles with greater emphasis on deep learning [36].

Study done by Johnson among $\mathbf{7 4}$ first year medical students of USA had tried to compare the learnign preferences of undergraduate students on the basis of way they were recruitment in medical college (regular vs alternate and alternate listed students were supposed to be academically challenged students). The students who matriculated from the alternate list 
had significantly different learning modes in several key areas from regular admission medical students. First, they were less likely to have a preference for multimodal learning than regular admitted medical students. Second, the larger number of auditory learners were found in the alternate group compared with traditional medical students. The alternate list learners were less likely to signify a preference for learning through presentations of visual information than typical medical students. On the basis of this result Visual materials for medical learning such as diagrams, photographs, and video clips that demonstrate procedures might not be effective for at-risk learners as intended by the educator. Conversely, courses that utilize manipulation, interaction, and active learning might have a greater likelihood of benefiting learners who experience academic challenge [34].

Study done by Samarakoon et al. (2013) among the different categories of medical student (first year, final year and post graudate) of Sri Lanka found that mode of learning was not consistent among the three groups. The majority of first year (69.9\%) and final year students (67.5\%) had multimodal learning styles, while among postgraduates, the majority were unimodal $(52.9 \%)$ learners. The proportion of unimodal learners was statistically similar between preclinical and clinical students $(p=0.79)$ while postgraduates were statistically more likely to be unimodal learners compared to the undergraduates $(p=0.019)$. Among the undergraduate unimodal students majority were auditory learners while in postgraduate majority were kinesthetic learners [36]. Pre-university education is often supplemented with private tuition classes and or larger lecture based classes which gets its credibility after successful performance in medical entrance examination which might be the cause of having auditor learners. Postgraduate training is largely based on the job training, with very little didactic learning. It could be the reason that postgraduate trainees would favour kinesthetic learning styles instead of auditory. Dramatic shift from multimodal to unimodal learning in postgraduate students was not well justified by the author but it was assumed that due to lack of time in clinical schedule and lack of didactic learning might be responsible for such type of shift. Need to compete for grade for undergraduate students unlike the postgraduate students might be the cause of such type of difference in unimodal leaning style as evidenced by the study done by Aaron in USA [37]. Unlike these reports the study done by whillier et al among 1st year to 5 th year chiropractic students showed that neither multimodal style nor unimodal style varied in subsequent year. Though this different finding was not justified by the author it might be due to the fact that chiropractic is a very hands-on profession, which would appeal to kinesthetic learners, who, thus, would then remain motivated throughout their training and is nearly similar in pattern of curriculum, which caused the student to follow what they took initially [30]. Further researches should be done to understand the shifting of learning style in different level of medical education.

\section{Learning style and age}

Age was considered as a factor for shifting of the learning method from one to another. Study done by Samarakoon reasoned the shifting of postgraduate student form multimodal to unimodal due to difference in age between undergraduate and postgraduate students which was around seven year [36]. While the study done by Whillier et al showed no significant difference between unimodal and multimodal learning styles from first year to fifth year. But there was significant difference in preferences for visual and read/write type of learning style as the age increases [30]. These results were just opposite as we compare the findings of the study done by Murphy et al. (among undergraduate dental student) and by El Tantawi (among postgraduate dental students). The age difference of the sample subjects of those two studies was around 5 year. This comparison showed that preferences for Kinesthetic and Aural increases as subjects were older and Visual and read/write presentations were decreasing in same pattern $[33,38]$. Though we could not find the solid statement to justify this contrary effect, but differences in subjects characteristics might be responsible for this difference. In the former one (by Whillier et al) subjects were from medical stream while in later case (Murphy et al., El Tantawi) subjects were from dentistry stream. Whether the difference in learning style was due to different level of medical education or due to increasing age was not clear so it necessitated the further research by taking account the both factors.

\section{Learning style and gender}

Debate regarding a gender gap in math and science is older one. This debate is further inflamed by questions regarding "innate differences" between males and females and theories that claimed that women were biologically incapable of reason [39]. However, despite the passions and political correctness, these are important questions that must be addressed by the academic community if we are to provide quality education [40]. There is a large body of literature available on gender differences in learning. It has been reported that males have a preference for rational evaluation and logic, whereas females use "elaborative" processing in which they tend to seek personal relevance or individual connections with the material being taught [41]. In addition, males are more achievement oriented, while females are more socially and performance oriented [42].

Study done by Mon et al. among 98 Malaysian preclinical students ( 33 male and 65 female) showed that more percentage of female prefer multimodal presentation while for male it was unimodal. In addition, female students had more diverse preferences than male students by having 10 out of the other 11 possible combinations in multimodal learning style, whereas the male students only had 5 out of the 11 combinations. In this study, there was no significant gender difference in the percentages of males and female students who preferred unimodal and multimodal styles of information presentation ( $P=0.263 ; \alpha=0.05)$ [43]. Study done by Baykarn and Nacar also cocluded that learning styles did not differ between male and female students ( $p>0.05)$ [24]. Similar conclusion was made by El Tantawi and Shenoy et al. $[32,33]$.

Similar to the study of Mon et al., study of Kharb et al. showed that learning style preferences in females were more variable than in males. VR and AR bimodal combination were only found in females. It was also observed that a significantly higher number of female students preferred the auditory mode of the learning style as compared to the males; whereas a significantly higher number of male students preferred the kinaesthetic mode ( $p$ value $<0.05$ ). In same study when the students were asked to choose the preferred mode of teaching-learning activity, among the female students, the second most preferred methodology was lectures, whereas the male students preferred self study following practicals/dissections as a first choice for both genders [19]. Similar types of preferences were also observed among final year medical students of Nigeria by J. Ubah [27]. This difference could 
be explained by the fact that higher numbers of female students had a preference for auditory and visual modalities. This indicated that the choice of the teaching methodologies was affected to a certain extent by the learning styles of the students. study done by Choudhary and Dullo to assess gender differences in learning style preferences among undergraduate physiology students of medical college Kota found that in contrast of females $(75.27 \%)$, the majority of males (92.98) preferred multiple modes of information presentation. As compared to males (7\%) the females (23.72\%) preferred information to be presented in a single mode. It shows a significant variation between genders for both unimodal and multimodal type of presentations $(p<0.05)$ [20]. Such significant difference in learning style preference between gender was also observed by the study of Ubah J [27].

A study done by Wehrwein et al. comparing the learning style between the students of two genders from Michegan State University showed that $54.2 \%$ of females and only $12.5 \%$ of males preferred a single mode of information presentation. Among the female students preferred presentation were more varied as the previous studies had shown with $0 \%$ for $\mathrm{A}$ to $33.3 \%$ for $\mathrm{K}$ while in male the preferred presentations were more evenly distributed (except for $0 \%$ for $\mathrm{V}$ ) with $4.2 \%$ for $\mathrm{A}, \mathrm{R}$ and $\mathrm{K}$. Furthermore, $45.8 \%$ of female and $87.5 \%$ of male respondents preferred multiple modes. In summary, a majority of male students preferred multimodal instruction, specifically, four modes (VARK), whereas a majority of female students preferred single-mode instruction with a preference toward K. Thus, it was concluded that male and female students significantly different learning styles [40]. Although female learners can use all of the sensory modes in learning, one mode is dominant and preferred. The study done by Breckler et al among premedical, predental and prescientist groups of students showed that more female had multimodal learning preferences than males. This result was different from the conclusion made from the previous studies in which females were supposed to be more preferred for unimodal as compared to males. When Breckler et al. try to investigate deep into the study samples by taking into account of intended carrier choices of sample subjects, the differences between the gender was actually due to differences in career choices [16]. Study done by Kumar among 208 third and fourth year medical students (104 males and 104 females) within the age ranging from 20 to 28 years from Mauritius showed that both males and females preferred multimodal learning. This modality preference was almost similar in both male (75\%) and female (74\%) students who preferred learning by utilizing all four sensory modalities (VARK) [35].

Study done by Slater et al among the students of first year medical students of Wayne state university reported a preference for learning that utilizes multiple sensory modalities over unimodal learning for both male and female. Females were more diverse than the male population in choosing the preferences, encompassing a broader range of sensory modality combinations within their preference profiles. Of the six possible bimodal combinations, five were represented in the female student population (VR, VK, $A R, A K$, and $R K$ ), but only two were represented in the male population (VA and VK). Of the four possible trimodal combinations, all four were represented in the female student population, but only three were represented in the male population (VAR, VAK, and VRK). Furthermore, $40 \%$ of female multimodal learners reported a preference for using all four sensory modalities (VARK). In contrast to the male population, in which well over half $(56.5 \%)$ of multimodal male learners reported using all four sensory modalities as their preference. The visual preference was common for both genders. Though these differences were noted, statistically no significant difference was found when compared between two genders [21].

Study done by Nuzhat et al. among 146 (74 male) fourth year and fifth year medical students of Saudi Arabia found that The percentages of male and female students who preferred multimodal preference were (males $79.7 \%$ and females $65.3 \%$ ) and unimodal styles of information presentation were (males $20.3 \%$ and females $34.7 \%$ ). All the six possible bimodal combinations of learning styles were represented in the female student population but only five were represented in the male population. All the possible trimodal combinations were represented in the male and female student population. Furthermore $32.2 \%$ of male students were multimodal learners in contrast to only $10.63 \%$ of female students who reported using all four sensory modalities as their preference. There was significant gender difference in the percentages of students who preferred certain combinations of multimodal style of information presentation $(p=0.043)$. but overall There was no significant gender difference in the percentages of students who preferred multimodal or unimodal styles of information presentation $(p=0.16)$ [44].

\section{Correlation of learning style with academic performance}

When instruction matched student's learning style preferences, students achieved higher scores than when mismatched $[45,46]$. When intended career of students were correlated with the learning style of students most of the students who chose medicine as a future career were found to be multimodal learners than other intended career. Male premedical students were roughly twice as likely to have multimodal learning preferences than nonpremedical male students [16]. Study done among the 155 Turkish students found no statistically significant difference between first-semester grade point averages and learning styles $(p>0.05)$ [24]. This finding was later justified by finding of the study done by Shenoy et al. among 200 junior Resident of India by correlating their academic grades with their preferred learning styles [32]. Absence of correlation between the learning style preferences and performances probably proved that no learning style was superior; learning in the preferred style only makes the learning easier and enjoyable. Study done by Turner et al. showed that there was no association between learning preference and the residents' anticipated career choice or level of training among the pediatric residents [31]. Similarly study done by B. Ramirez among three cohorts of second year medical students showed that there was no significant correlation between the score they got from multiple choice questions (MCQs) and their preferred learning style for both unimodal and multimodal presentation [25].

On the other hand Study done by El Tantawi among postgraduate dental students showed that statistically significant difference was observed between students with single and multiple preferences since students with multiple preferences had a score about six points higher than that of students with single preferences $(87.09 \pm 7.29$ and $81.05 \pm 9.11$, respectively). Statistically significant differences were observed between students with and without different learning preferences (visual, aural, read-write, and kinesthetic), in which students who had a specific learning preference had significantly higher scores than students who did not $(P=0.02,0.006,0.04$, and 0.03 , respectively). Regression analysis showed that Aural preference was one of the predictors predicting final exam score along with other variables (bachelor's 
degree score and quiz score) [33]. Study done by Marcy V among first year Physical Assistant students showed that after the intervention of VARK, it could increase the student's learning. But the obvious limitation of the study was very less sample size and the observation of such benefit was on the basis of feedback from the students [6]. Study of Nuzhat et al. showed that multimodal learners were found to be achieved higher grade as compared to unimodal learners for both male and female [44]. Similar studies relating course scores with sensory modalities have found either no relation [24], or that unimodal students have achieved comparatively lower scores than multimodal students [33], so the effect of learning style preferences on academic performance needs further investigation.

\section{Acknowledgments}

Authors want to thank all the seniors and friends who help finding resources and gave idea for writing the review

\section{Conflict of interest}

Authors declared that there was no conflict of interest.

\section{References}

1. Fulton JF. History of medical education. Br Med J 1953; 2(4834): 45761. (PMID: 13066760)

2. Langdon-brown PW. Trotula and the ladies of Salerno: a contribution to the knowledge of the transition between ancient and medieval physick. Proc R Soc Med 1940; 33(8): 471-475.

3. Howell JD. Histories of academic medical education. Acad Med 1995; 70(8): 692-695. (PMID: 7646743)

4. Weatherall DJ. Science in the undergraduate curriculum during the 20th century. Med Educ 2006; 40(3): 195-201. (PMID: 16483321) (doi: 10.1111/j.1365-2929.2006.02399.x)

5. Choudhary R, Dullo P, Gupta U. Attitude of 1st year MBBS medical students about two different visual aids in physiology lectures. Pak J Physiol 2009; 5(2): 16-19.

6. Marcy V. Adult Learning Styles: How the VARK $^{\odot}$ learning style inventory can be used to improve student learning. J Assoc Physician Assist Programs 2001; 12(2): 1-5.

7. Vaughn L, Baker R. Teaching in the medical setting: balancing teaching styles, learning styles and teaching methods. Med Teach 2001; 23(6): 610-612. (PMID: 12098485) (doi: 10.1080/01421590120091000)

8. Davis BG. Tools for Teaching. 2nd ed. San Francisco: Jossey-Bass, 2009; $608 \mathrm{p}$.

9. Shankar PR, Dubey AK, Binu VS, Subish P, Deshpande VY. Learning styles of preclinical students in a medical college in western Nepal. Kathmandu Univ Med J (KUMJ) 2006; 4(3): 390-395. (PMID: 18603940)

10. Engels PT, de Gara C. Learning styles of medical students, general surgery residents, and general surgeons: implications for surgical education. BMC Med Educ 2010; 10(1): 51. (PMID: 20591159) (doi: 10.1186/1472-6920-10-51)

11. Coffield F, Moseley D, Hall E, Ecclestone K. Learning styles and pedagogy in post-16 learning: A systematic and critical review. London, 2004; $182 \mathrm{p}$.

12. Newble DI, Entwistle NJ. Learning styles and approaches: implications for medical education. Med Educ 1986; 20(3): 162-175. (PMID: 3724571)

13. Fleming $N$, Baume D. Learning Styles Again: VARKing up the right tree! Educational Developments, SEDA Ltd 2006; (7): 4-7.

14. Fleming ND, Mills C. Not Another Inventory, Rather a Catalyst for Reflection. To Improv Acad 1992; 1(1): 137-144.

15. Newble DI, Gordon MI. The learning style of medical students. Med Educ 1985; 19(1): 3-8. (PMID: 3969021)
16. Breckler J, Joun D, Ngo H. Learning styles of physiology students interested in the health professions. Adv Physiol Educ 2009; 33(1): 3036. (PMID: 19261758) (doi: 10.1152/advan.90118.2008)

17. Kumar LR, Chacko TV. Using appreciative inquiry to help students identify strategies to overcome handicaps of their learning styles. Educ Health (Abingdon) 2012; 25(3): 160-164. (PMID: 23823635) (doi: 10.4103/1357-6283.109794)

18. Lujan HL, Di Carlo SE. First-year medical students prefer multiple learning styles. Adv Physiol Educ 2006; 30(1): 13-16. (PMID: 16481603) (doi: 10.1152/advan.00045.2005)

19. Kharb P, Samanta PP, Jindal M, Singh V. The learning styles and the preferred teaching-learning strategies of first year medical students. $J$ Clin Diagn Res 2013; 7(6): 1089-1092. (PMID: 23905110) (doi: 10.7860/JCDR/2013/5809.3090)

20. Choudhary R, Dullo P. Gender differences in learnign style preferences of first year medical students. Pak J Physiol 2011; 7(2): 42-45.

21. Slater JA, Lujan HL, DiCarlo SE. Does gender influence learning style preferences of first-year medical students? Adv Physiol Educ 2007; 31(4): 336-342. (PMID: 18057406) (doi: 10.1152/advan.00010.2007)

22. Pashler $H$, McDaniel $M$, Rohrer D, Bjork R. Learning styles concepts and evidence. Psychol Sci Public Interes 2008; 9(3): 105-119.

23. Fleming ND. Teaching and learning styles: VARK strategies. New Zeland, 2001; 128 p

24. Baykan Z, Naçar M. Learning styles of first-year medical students attending Erciyes University in Kayseri, Turkey. Adv Physiol Educ 2007; 31(2): 158-160. (PMID: 17562904) (doi: 10.1152/advan.00043.2006)

25. Ramirez BU. The sensory modality used for learning affects grades. Adv Physiol Educ 2011; 35(3): 270-274. (PMID: 21908836) (doi: 10.1152/advan.00010.2011)

26. Hamouzadeh $P$, Pourreza A, Panahi M, Salimi M. Learning styles of health services management students at Tehran University of Medical Sciences. Hosp (Lond 1886) 2011; 10(4): 37-44.

27. Ubah JN. Learning styles among medical students, a case study of Ladoke Akintola University of Technology Medical School, Osogbo, Western Nigeria. J Educ Pract 2012; 3(5): 47-51.

28. Sinha NK, Bhardwaj A, Singh S, Abas AL. Learning preferences of clinical students: A study in a Malaysian medical college. Int J Med Public Heal 2013; 3(1): 60-63.

29. Dobson JL. A comparison between learning style preferences and sex status, and course performance. Adv Physiol Educ 2010]; 34(4): 197204. (PMID: 21098387) (doi: 10.1152/advan.00078.2010)

30. Whillier S, Lystad RP, Abi-Arrage D, McPhie C, Johnston S, Williams C, Rice $M$. The learning style preferences of chiropractic students: A cross-sectional study. J Chiropr Educ 2014; 28(1): 21-27. (PMID: 24350945) (doi: 10.7899/JCE-13-25)

31. Turner DA, Narayan AP, Whicker SA, Bookman J, McGann KA. Do pediatric residents prefer interactive learning? Educational challenges in the duty hours era. Med Teach 2011; 33(6): 494-496. (PMID: 21355697) (doi: 10.3109/0142159X.2010.542524)

32. Shenoy N, Shenoy K A, U P R. The perceptual preferences in learning among dental students in clinical subjects. J Clin Diagn Res 2013; 7(8): 1683-1685. (PMID: 24086874) (doi: 10.7860/JCDR/2013/4940.3219)

33. El Tantawi MM. Factors affecting postgraduate dental students' performance in a biostatistics and research design course. J Dent Educ 2009; 73(5): 614-623. (PMID: 19433536)

34. Johnson M. Evaluation of learning style for first year medical students. Int J Scholarsh Teach Learn 2009; 3(1): 20.

35. Kumar AA. An Analysis of gender differences in learning style preferences among medical students. Indian J Forensic Med Pathol 2012; 5(1): 9-16

36. Samarakoon L, Fernando T, Rodrigo C. Learning styles and approaches to learning among medical undergraduates and postgraduates. BMC Med Educ 2013; 13: 42. (doi: 10.1186/1472-6920-13-42) (PMID: 23521845) 
37. Aaron S, Skakun E. Correlation of students' characteristics with their learning styles as they beginmedical school. Acad Med 1999; 74(3): 260-262.

38. Murphy RJ, Gray SA, Straja SR, Bogert MC. Student learning preferences and teaching implications. J Dent Educ 2004; 68(8): 859866. (PMID: 15286109)

39. Glazer S. Gender and learning: are there innate differences between the sexes? CQ Res 2005; 15: 445-468.

40. Wehrwein EA, Lujan HL, DiCarlo SE. Gender differences in learning style preferences among undergraduate physiology students. Adv Physiol Educ 2007; 31(2): 153-157. (PMID: 17562903) (doi: 10.1152/advan.00060.2006)

41. Lie L, Angelique L, Cheong E. How do male and female students approach learning at NUS? CDTL Br 2004; 7: 1-3.

42. Chang W. Learning goals and styles by gender a style of NUS students. CDTL Br 2004; 7: 4-5.

43. Mon AA, Fatini A, Ye CW, Barakat MA, Jen PL, Lin TK. Learning style preferences among pre-clinical medical students. J Med Allied Sci 2014; 4(1): 22-27.

44. Nuzhat A, Salem RO, Al Hamdan N, Ashour N. Gender differences in learning styles and academic performance of medical students in Saudi Arabia. Med Teach 2013; 35(suppl 1): S78-S82. (PMID: 23581901) (doi: 10.3109/0142159X.2013.765545)

45. Mangino C, Griggs S. Learning styles model research: Who, what, when, where and so what the dunn and dunn learning styles model and its theoretical corner stone. R. Dunn and S. Griggs eds. New York, 2003.

46. Millar J. Enhancement of achievement and attitudes through individual learning-style presentations of two allied health courses. J Allied Heal 1998; 27: 150-156.

Authors:

Dr Laxman Khanal - BDS, MS (Human Anatomy), BP Koirala Institute of Health Sciences, Dharan, Nepal.

Dr Sandip Shah - Assistant professor (Human Anatomy), BP Koirala Institute of Health Sciences, Dharan, Nepal.

Dr Sarun Koirala - Assistant professor (Human Anatomy), BP Koirala Institute of Health Sciences, Dharan, Nepal. 